\title{
FORMAÇÃO E CONTEXTOS DE ATUAÇÃO DE PROFESSORES NA EDUCAÇÃO DE JOVENS E ADULTOS: Os Desafios da Docência
}

\author{
Andréa Souza de Albuquerque ${ }^{1}$ \\ Tadeu Oliver Gonçalves² \\ Jaqueline Castro Baía Rocha ${ }^{3}$
}

\begin{abstract}
RESUMO
Este estudo tem como objetivo investigar a formação e o contexto de atuação pedagógica de professores na educação de jovens e adultos, e conhecer a realidade deste ensino na perspectiva dos professores tanto em relação ao papel da escola quanto aos desafios e possibilidades dos que atuam nessa modalidade. Como perguntas centrais definimos: Qual o perfil dos docentes que atuam na EJA? Qual o contexto de atuação dos docentes nas escolas que ofertam turmas de EJA? Quais as principais dificuldades e desafios que os professores enfrentam em relação à escola durante sua atuação nas turmas com jovens e adultos? A pesquisa teve abordagem qualitativa, sendo realizada uma entrevista semiestruturada com três docentes que atuam em uma escola municipal da rede de ensino de Belém/PA, no período noturno, que ofertam a modalidade educativa voltada para atender jovens e adultos. Os resultados indicam que os professores se sentiram desvalorizados e desmotivados a buscar novas metodologias capazes de modificar as propostas pedagógicas tradicionais em virtude da falta de apoio da gestão das escolas e da Secretaria Municipal de Educação, falta de recursos pedagógicos necessários e de uma formação inicial continuada para atender às especificidades deste ensino. Diante desta realidade, é urgente que as escolas e os professores repensem e ressignifiquem suas práticas metodológicas e de gestão da escola quanto às singularidades dos educandos, os quais ainda têm sido considerados sujeitos "invisíveis" em relação ao seu direito de acesso a uma educação pública de qualidade em nosso país.

Palavras-chave: Educação de Jovens e Adultos. Atuação docente. Desafios.
\end{abstract}

\section{FORMATION AND CONTEXTS OF TEACHERS' PERFORMANCE IN YOUTH AND ADULT EDUCATION:} THE CHALLENGES OF TEACHING

\section{ABSTRACT}

This study aims to investigate the formation and context of pedagogical performance of teachers in the education of young people and adults, to know the reality of this teaching in the perspective of the teachers both in relation to the role of the school, as well as the challenges and possibilities of those who work in this modality. As central questions we define: What is the profile of teachers who work at EJA? What is the context in which teachers work in schools that offer EJA classes? What are the main difficulties and challenges that teachers face in relation to the school during their work in classes with young people and adults. The research had a qualitative approach, being carried out a semi-structured interview with three teachers who work at a municipal school in the Belém/PA education network, in the evening, who offer the educational modality aimed at serving youth and adults. The results indicate that teachers felt devalued and discouraged from seeking new methodologies capable of modifying traditional pedagogical proposals due to the lack of support from the management of schools and the Municipal Secretariat of Education, lack of necessary pedagogical resources and of a continuous initial training to meet the specificities of this teaching. In view of this reality, it is urgent that schools and teachers rethink and reframe their methodologies and school management practices regarding the singularities of students who have still been considered as "invisible" subjects in relation to their right of access to quality public education in our country.

Keywords: Youth and Adult Education. Teaching Performance. Challenges.

Recebido em: $14 / 3 / 2020$

\footnotetext{
Doutoranda pelo Programa de Pós Graduação em Educação em Ciências e Matemática da Universidade Federal do Pará. Mestre em Educação (Uepa). Pedagoga da Universidade do Estado do Pará. Professora e Coordenadora Curso de Gestão Educacional e Coordenação Pedagógica do Centro Universitário Fibra. Pesquisa sobre: Ensino, Formação de Professores, Políticas Públicas Educacionais, Educação de Jovens e Adultos. http://lattes.cnpq.br/8631288804274692. https://orcid.org/0000-0001-8086-165X. andasouza2014@gmail.com

2 Doutor em Educação Matemática pela Universidade Estadual de Campinas (2000). Professor da Universidade Federal do Pará. Docente e pesquisador do Programa de Pós-Graduação em Educação em Ciências e Matemática (PPGECM/IEMCI/UFPA) e do Programa de PósGraduação em Educação em Ciências e Matemática - Rede Amazônica de Educação em Ciências e Matemáticas (Reamec). Pesquisa a Formação de Formadores e de Professores de Matemática, ensino e educação matemática e neurociência. http://lattes.cnpq. br/6789250569319668. http://orcid.org/0000-0002-2704-5853. tadeuoliver@yahoo.com.br

Graduanda em Licenciatura em Pedagogia do Centro Universitário Fibra. jaquelinecbr86@gmail.com
} 
Aceito em: 17/4/2020

Este estudo é fundamentado na busca de conhecer historicamente o processo de formação dos docentes, fazendo uma breve discussão acerca das principais características e especificidades do ensino de jovens e adultos e de suas funções, conforme estabelecido no Parecer $n^{\circ} 1 / 2000$ acerca das Diretrizes Curriculares Nacionais para o ensino de jovens e adultos no Brasil (BRASIL, 2000) e a Resolução no 020/2011, do Conselho Municipal de Educação de Belém (CMEB) (BELÉM, 2011).

Além disso, o estudo tomou como base teórica determinados autores (FREIRE, 1991, 2005; SCHEIBEL; LEHENBAUER, 2010; RIBEIRO, 2006; MAIA, 2010; GADOTTI; RO$M A ̃ O, 2002)$ que contribuíram para a discussão em torno do processo de aprendizagem de alunos jovens e adultos, bem como do papel da escola e dos demais atores envolvidos nessa modalidade de ensino, apontando algumas possibilidades e expectativas quanto aos saberes e singularidades envolvidos nesse processo.

A metodologia privilegiou a abordagem qualitativa. A escola, local da pesquisa, fica localizada no Bairro do Guamá/Belém, e foi campo de estágio supervisionado em Gestão Escolar no Curso de Pedagogia do Centro Universitário Fibra de uma das autoras deste artigo, ainda graduanda em Pedagogia, a qual conseguiu autorização da Direção para convidar os professores da EJA a participar das entrevistas.

Em 2019, a escola municipal dispunha de 12 salas de aulas, atendendo nos 3 turnos: manhã, tarde e noite. No período diurno ofertava o Ensino Fundamental do 1 응 a 9o ano, em ciclos de Formação, amparados pela Resolução 040/2011, e, no noturno, ofertava a Educação de Jovens e Adultos (EJA) na proposta das Totalidades, amparados pela resolução 020/2011, ambas do Conselho Municipal de Educação de Belém (CME).

O quantitativo de alunos, no período da manhã, era de 354 alunos de 1 음 a 5 ㅇ ano com faixa-etária de 6 a 10 anos. No turno vespertino, havia 397 alunos matriculados do 60 ao 90 ano, na faixa-etária de 11 a 14 anos, e no noturno havia 427 alunos matriculados a partir de 15 anos de idade, conforme dados disponibilizados pela gestora da escola.

O contexto da Educação de Jovens e Adultos na escola em 2019 era composta por 11 turmas, subdivididas em: 1 - primeira totalidade; 2 - segunda totalidade; 3 - terceira totalidade; e 4 - quarta totalidade. Na primeira e segunda totalidades, o corpo docente era composto por professores de Artes, Educação Física, Educação Geral Fundamental e Ensino Religioso; na terceira e quarta etapas havia professores de 11 disciplinas: Artes, Ciências, Educação Física, Ensino Religioso, Geografia, História, Língua Estrangeira Moderna (Inglês), Língua Portuguesa, Matemática, Filosofia e Sociologia. Era a única escola do Bairro do Guamá a ofertar turmas de EJA, com corpo docente composto por professores efetivos da Rede Municipal de Educação, conforme sinalizou a gestora da escola.

O corpo docente contava em seu quadro com 20 professores efetivos da Rede, atuando em diversas disciplinas da EJA, os quais foram convidados a participar das entrevistas semiestruturadas na busca de informações relacionadas ao perfil docente, formação, qualificação e contextos de atuação, e à postura desses docentes ante a sua atuação nas turmas que atendem jovens e adultos, considerando as particularidades vividas diariamente nesta modalidade de ensino. 
Em razão da urgência e necessidade da realização da pesquisa e do levantamento dos dados, foram selecionados três dias da semana, de forma aleatória, pelos pesquisadores, para a realização das entrevistas, momento em que foram entrevistados três docentes, dentre os voluntários que se dispuseram a responder os questionamentos, sendo dois entrevistados com áudio gravado e um aceitando participar somente por meio de respostas manuscritas, sem gravação de áudio.

A partir do referencial teórico foram analisadas as entrevistas realizadas com os docentes da EJA da instituição municipal de ensino em seu processo de formação. Delineou-se ainda a observação do contexto escolar a fim de compreender melhor o contexto de atuação, os projetos existentes e as perspectivas relatadas pelos docentes quanto a essa modalidade de ensino.

Considerando a crescente necessidade de debater e refletir acerca da realidade do ensino voltado para jovens e adultos e suas peculiaridades no atual cenário educacional brasileiro, esta investigação tem como objetivo compreender o contexto de atuação de três docentes que desenvolvem o ensino nas turmas de EJA na Rede Municipal de Educação da cidade de Belém, e buscar investigar os principais desafios enfrentados cotidianamente por estes docentes.

\section{A MODALIDADE DE ENSINO PARA JOVENS E ADULTOS E A LEGISLAÇÃO}

No Brasil cabe pontuar, inicialmente, a Constituição Federal Brasileira de 1988, nos artigos 206 e 208, inciso I, que inclui o ensino de jovens e adultos no rol de direitos educacionais a serem garantidos, com igualdade de condições de acesso e permanência nas escolas, obrigatoriedade e gratuidade (BRASIL, 1988).

A Lei de Diretrizes e Bases da Educação Nacional - LDB (Lei 9.394/96) define o ensino para jovens e adultos como uma modalidade da educação básica correspondente às etapas do Ensino Fundamental e Médio, conforme disciplina a matéria na seção V Da Educação de Jovens e Adultos, nos artigos 37 e 38 e seus parágrafos (BRASIL, 1996).

Considerando as especificidades deste ensino, voltado para o atendimento a jovens e adultos, em complementação à $L D B$, foi então homologado o Parecer CNE/CEB no 1/2000, acerca das Diretrizes Curriculares Nacionais para o ensino de jovens e adultos, definindo as funções correspondentes a esta modalidade de ensino (BRASIL, 2000).

Destacam-se três aspectos das Diretrizes Curriculares Nacionais para o ensino de jovens a adultos, com o intuito de resgatar o direito à cidadania desses estudantes: i) sua função reparadora, que representa a entrada do ensino de jovens e adultos no campo do direito civil, com reparação de dívida histórica e social, propondo a igualdade de oportunidade; ii) função equalizadora, que parte do princípio da equidade e possibilita o reingresso no sistema educacional, dando a oportunidade de melhorias sociais, econômicas e educacionais iii) função qualificadora, que visa a propiciar a atualização de conhecimentos por toda a vida, objetivando a educação permanente, diversificada e universal.

Essas funções distinguem-se em essência, mas se entrelaçam e se complementam, estando diretamente relacionadas com as especificidades características do ensino para jovens e adultos. 
A proposta de organização da EJA da Secretaria Municipal de Educação, em totalidade do conhecimento, defende a ideia de compreender a interação das partes com o todo, visando a quebrar a lógica tradicional que se estrutura a partir das grades curriculares rigidamente organizadas, para pautar-se na concepção de busca do conhecimento enquanto totalidade, devendo a educação de jovens e adultos assumir, no seu conjunto, um caráter interdisciplinar e contextualizado (SEMEC, 2002).

A Resolução n 020/2011, do Conselho Municipal de Educação de Belém (CMEB), estabelece as Diretrizes para o ensino voltado para atender jovens e adultos no município de Belém, $\mathrm{O}$ artigo $9^{\circ}$ dispõe que a organização da EJA constitui-se de 4 anos letivos sequenciais, identificados como Totalidades do conhecimento, sendo: i) Totalidade equivalente ao $1^{\circ}, 2^{\circ}$ e $3^{\circ}$ anos; ii) Totalidade, equivalente ao $4^{\circ}$ e $5^{\circ}$ anos; iii) Totalidade/Etapa, ao $6^{\circ}$ e $7^{\circ}$ anos e iv) Totalidade/Etapa ao $8^{\circ}$ e $9^{\circ}$ anos.

0 artigo $6^{\circ}$ da mesma Resolução estabelece que o ensino de jovens e adultos é organizado em estudos presenciais, compreendendo o mínimo de três horas diárias e estudos extraclasses, somando, pelo menos, cinco horas semanais, a serem planejadas e cumpridas com metodologias e atividades compatíveis com as necessidades dos alunos e as possibilidades da escola.

Considerando a legislação vigente, Maia (2010) pontua os objetivos do ensino voltado para atender adolescentes e adultos que, historicamente, visa a atenuar os processos de exclusão e marginalização social que sofriam e sofrem os jovens e adultos que se encontravam e se encontram fora da escola, oportunizando educação formal para sujeitos que não tiveram escolarização na idade regular.

Por fim, Maia (2010) ressalta a existência de um movimento que tem levado um público cada vez mais jovem às turmas de educação de jovens a adultos, de modo que o perfil de estudantes nessa modalidade de ensino tem mudado, uma vez que a cultura juvenil tem tomado as salas de aula no turno noturno em razão da evasão escolar multifatorial, reprovações excessivas e práticas educativas inadequadas, fatores que os impedem ou os desmotivam a continuar na escola na idade certa no ensino regular.

Três grandes questões sociais fazem com que, todos os anos, muitos estudantes desistam de estudar: a vulnerabilidade social, o uso de drogas e a exploração juvenil, pois enfrentam problemas decorrentes da pobreza extrema. A necessidade de trabalho é outra situação que os leva a deixar a escola na idade regular, a fim de contribuírem de alguma forma com a renda familiar, o que faz com que muitos alunos deixem de frequentar as aulas do Ensino Fundamental antes de concluí-lo.

A dificuldade de conciliar os estudos com o trabalho também faz com que mudar para as turmas do ensino de jovens e adultos, sobretudo no período noturno, seja a única opção. Como último fator a ser destacado, tem-se a gravidez precoce, pois com a chegada do primeiro filho muitas adolescentes se afastam da sala de aula e, quando conseguem, retornam à escola tempos depois, indo para turmas de jovens e adultos.

Desta forma, foi observado que a educação tardia de jovens e adultos se relaciona diretamente à situação econômica destes, ao mesmo tempo em que a desigualdade social é um problema ainda maior do que o próprio analfabetismo. A educação sozinha, 
portanto, não irá solucionar todos os problemas socioeconômicos, uma vez que as práticas sociais acabam contribuindo para a segregação de sujeitos considerados analfabetos, analfabetos funcionais e em processo de letramento.

Diante dessas legislações combinadas - Constituição Federal/1988, artigo 206 e 208; LDNEB - Lei 9.394/96, artigo 37 e 38; e Parecer CNE/CEB, n. 1/2000 (BRASIL, 1988, 1996, 2000) - vemos que se mantêm fiéis ao objetivo de propiciar a educação de forma justa, democrática e acessível a todos, inclusive àqueles que a ela não tiveram ingresso na idade própria, democratizando o acesso à educação como direito à cidadania.

No cenário contemporâneo a EJA, ofertada nas escolas, volta-se para a construção da cidadania, oferecendo aos jovens e adultos a possibilidade de ampliar a aprendizagem dos conteúdos escolares, bem como de aumentar a consciência em relação à interação com o mundo, desenvolvendo a capacidade de maior participação social no exercício da cidadania.

\section{O EDUCADOR QUE ATUA NO ENSINO DE JOVENS E ADULTOS E SUAS APRENDIZAGENS}

Considerando o avanço e a popularização do ensino de jovens e adultos, Ehrhardt (2010) analisa o educador que atende a estas turmas na estrutura do ensino formal, a fim de compreender quem são esses professores e de que forma o fazer pedagógico os constitui. Para isso, apresenta depoimentos de professores que atuam no atendimento a jovens e adultos em encontros de capacitação, que correspondem a momentos de encontro entre educadores, que favorecem a reflexão-ação das práxis docentes, potencialmente importante e tão necessária ao fazer pedagógico.

Diante das falas selecionadas pelos autores durante os eventos e em registros escritos, foi observado que o ensino para jovens e adultos se tornou um momento marcante da trajetória pessoal e profissional dos educadores, uma vez que se vislumbra em cada registro diversos relatos de experiências vivenciadas por professores, que revelaram uma reconstrução de seu papel docente como alguém que deve ajudar o aluno a aprender e que também deve aprender com o aluno.

Esse novo olhar dos educadores quanto ao seu papel, em uma nova visão de educação, somente é possível diante de uma docência em que a afetividade é a palavra-chave para esse redimensionamento, posto que será o alicerce para as relações entre esse educador e os seus alunos.

A metodologia de pesquisa adotada neste estudo quanto à aplicação de questionários e entrevistas com docentes que atuam no ensino de jovens e adultos, permite a reflexão quanto às possibilidades e desafios da profissão, especialmente nesta modalidade de ensino. Nesta mesma perspectiva de aprendizagens, Rosa (2010) leva a refletir sobre a importância do exercício do pensamento, reflexão, problematização e ação sobre a própria prática, seja como educador ou como formador, pois as práticas docentes e as experiências sustentarão as intervenções pedagógicas que os diferentes saberes e a subjetividade de cada educador consideram relevantes. 
Ao considerarmos a prática docente dos professores dessa modalidade de ensino, percebemos o quanto ela é especialmente impregnada de valores, normas, tradições e experiências de vida que são reinventados constantemente. Desta forma, o professor se torna sujeito ativo da sua própria prática.

Diante disso, redescobrir e ressignificar as práticas docentes corresponde ao fio condutor da formação continuada no ensino de jovens e adultos. Assim, o professor deve ser capaz de refletir sobre a sua prática, ressignificando-a conforme a realidade em que atua, atentando para os interesses e cultura do seu aluno, uma vez que, conforme Freire (1991, p. 80), “[...] a formação do educador deve instrumentalizá-lo para que ele crie e recrie a sua prática através da reflexão sobre o seu cotidiano".

$\mathrm{Na}$ prática, isso acontece por meio da construção das identidades profissionais docentes, em que a formação continuada deve ser entendida como um espaço permanente de reflexão crítica, de problematização, de discussão e de trocas entre educadores, fortalecendo a integração entre a teoria e a prática pedagógica. Além disso, é importante ressaltar a responsabilidade das instituições das esferas públicas e privadas por proporcionar essa formação continuada, essencial para a profissionalização dos educadores, flexibilizando as fronteiras entre o currículo e a formação docente.

Nesse sentido, é imprescindível incluir em nossa análise a descrição da realidade da atividade docente sob o olhar dos próprios professores, incluindo suas principais dificuldades profissionais no exercício da docência, a importância da formação continuada nesse processo e quais os principais desafios enfrentados em relação à escola e aos alunos durante a atuação nas turmas de ensino de adolescentes e adultos.

\section{PERFIL DOS DOCENTES QUE ATUAM NO ENSINO DE JOVENS E ADULTOS EM UMA ESCOLA DA REDE MUNICIPAL DE BELÉM/PA}

A pesquisa empírica partiu dos seguintes objetivos: i) conhecer o perfil, a formação e o contexto de atuação pedagógica de professores no ensino de adolescentes e adultos; ii) compreender melhor a perspectiva dos professores sobre a realidade do atual cenário desta modalidade de ensino, tanto em relação ao papel da escola quanto às particularidades, desafios e possibilidades dos sujeitos envolvidos neste ensino.

Neste sentido, e no intuito de complementarmos nossa investigação teórica, foram realizadas entrevistas com três professores que atuam no ensino de jovens e adultos em uma escola da rede municipal de ensino, localizada no bairro do Guamá, na cidade de Belém/PA.

Por meio das entrevistas foi possível identificar a formação e o contexto de atuação de cada um dos professores, enfatizando questionamentos de nossa investigação quanto à relação entre a formação docente (inicial e continuada) e seu contexto de atuação. Com isso, também se pôde buscar analisar os contextos e sujeitos envolvidos nessa modalidade de ensino, sob o olhar dos professores entrevistados, observando se essa atuação dialoga verdadeiramente com a proposta de aprendizagem significativa, a qual deve ir além dos conteúdos formais e ser adequada às especificidades e singularidades de jovens e adultos. 
Assim, após cada quadro com a transcrição das respostas dos professores entrevistados, segue uma breve análise sobre cada tópico dos questionários respondidos. Ressalta-se que, para salvaguardar o anonimato dos participantes da entrevista, os professores voluntários foram denominados P1, P2 e P3.

\section{QUEM SÃO OS DOCENTES QUE ATUAM NO ENSINO DE JOVENS E ADULTOS}

A análise é iniciada traçando um breve perfil dos professores entrevistados. 0 Quadro 1 mostra que estes possuem diferentes tempos de experiência profissional na instituição. O professor $\mathrm{P} 1$ possui 11 anos de atuação na escola, enquanto os professores P2 e P3 atuam há 6 anos na instituição, sendo importante salientar que os três professores trabalham em disciplinas de acordo com a sua formação acadêmica - Ciências, Educação Física e Pedagogia - e se encontram, para efeito de caráter didático e metodológico nesta análise, em uma fase classificada como professor em anos intermediários de carreira (PAT), a qual compreende um período de 6 a 15 anos de atuação docente.

Quadro 1 - Perfil dos docentes entrevistados

\begin{tabular}{|c|c|c|c|c|c|c|}
\hline Docente & Sexo & $\begin{array}{c}\text { Faixa } \\
\text { etária } \\
\text { (anos) }\end{array}$ & $\begin{array}{c}\text { Disciplina } \\
\text { que } \\
\text { ministra/ } \\
\text { área de } \\
\text { atuação }\end{array}$ & $\begin{array}{c}\text { Tempo } \\
\text { total de } \\
\text { atuação na } \\
\text { escola }\end{array}$ & $\begin{array}{c}\text { No de } \\
\text { Turmas }\end{array}$ & Carga horária \\
\hline P1 & M & $45-50$ & Ciências & 11 anos & $\begin{array}{c}5 \text { (tarde) } \\
3 \text { (noite) }\end{array}$ & 24 horas semanais \\
\hline P2 & M & $31-35$ & $\begin{array}{c}\text { Educação } \\
\text { Física }\end{array}$ & 6 anos & $\begin{array}{c}2 \text { (tarde) } \\
\text { (noite) } \\
3 \text { (projeto) }\end{array}$ & 15 horas semanais \\
\hline P3 & F & $31-35$ & $\begin{array}{c}\text { Pedagogia } \\
\text { (1a etapa) }\end{array}$ & 6 anos & 1 (noite) & 20 horas semanais \\
\hline
\end{tabular}

Fonte: Elaborado pelos autores com base nos questionários aplicados aos docentes.

A experiência profissional dos docentes carrega consigo suas vivências individuais e coletivas, as quais são constituídas no cotidiano de sua atuação e construídas em diferentes momentos e espaços de sua carreira. Este é um processo de construção que constitui o professor como sujeito no ensino e aprendizagem, a partir da internalização dos significados de suas experiências e vivências em seu percurso acadêmico e docente.

A partir desse perfil inicial dos professores entrevistados, foi realizada uma análise mais aprofundada em relação à sua atuação docente, percepções educacionais, anseios, projeção de carreira, experiências, metodologias, conteúdo, desafios e necessidades, em especial no que se refere à atuação no ensino de adolescentes e de adultos na instituição onde trabalham atualmente.

\section{Formação inicial dos docentes que atuam no ensino de jovens e adultos}

A fim de buscar a compreensão da relação entre a formação dos professores entrevistados e suas práticas pedagógicas nas turmas de Educação de Jovens e Adultos (EJA), apresentamos a formação acadêmica inicial destes. 
Considerando as singularidades e as particularidades dos alunos do EJA, salienta-se que, apesar de todos os professores possuírem Ensino Superior completo em suas disciplinas de atuação (Quadro 2), apenas dois possuem especialização, e nenhum dos três têm algum tipo de Pós-Graduação voltado especificamente para o ensino de adolescentes e adultos ou formação equivalente.

Quadro 2 - Formação inicial dos docentes entrevistados

\begin{tabular}{|c|c|c|c|}
\hline Docente & Ensino Superior & $\begin{array}{c}\text { Pós-Graduação } \\
\text { (Lato senso) }\end{array}$ & $\begin{array}{c}\text { Pós-Graduação } \\
\text { (Strictu senso) }\end{array}$ \\
\hline P1 & Completo & $\begin{array}{c}\text { Educação de Ciências e } \\
\text { Matemática }\end{array}$ & Não possui \\
\hline P2 & Completo & Educação Especial & Não possui \\
\hline P3 & Completo & Não possui & Não possui \\
\hline
\end{tabular}

Fonte: Elaborado pelos autores com base nos questionários aplicados aos docentes.

Santos (1998) aponta a importância do investimento na formação inicial docente, pois se o professor detém uma sólida formação teórica, por conseguinte terá melhores condições de analisar e criticar projetos educacionais.

É importante mencionar que os cursos de Pós-Graduação são essenciais para um novo olhar sobre a perspectiva docente dos professores, em relação a sua postura, pesquisa, orientação e concepção de educação, portanto, são um fator potencialmente transformador na percepção de sua carreira na atuação docente. A oferta de cursos de Pós-Graduação voltados para as especificidades do ensino de adolescentes e de adultos, contudo, ainda é bastante escassa no Brasil.

Os professores que atuam no ensino de adolescentes e adultos buscam alternativas quanto à formação acadêmica voltada para atender este público específico, visando ao melhor preparo e dinamismo tanto para atuar nesta modalidade de ensino quanto para compreender a diversidade de sujeitos, o que exige atualização profissional contínua e proposição de novas metodologias, a fim de alcançar os diferentes níveis educacionais em que os alunos se encontram.

\section{FORMAÇÃO CONTINUADA DOS DOCENTES QUE ATUAM NO ENSINO DE JOVENS E ADULTOS}

Aos professores foi feito o seguinte questionamento: "Neste momento você está realizando alguma formação continuada para o melhor desenvolvimento do seu trabaIho docente? Se afirmativo, qual? Quais cursos você apontaria ou gostaria de fazer?" As respostas estão transcritas no Quadro 3. 
Quadro 3 - Formação continuada dos docentes entrevistados

\begin{tabular}{|c|l|}
\hline Docente & \multicolumn{1}{|c|}{ Fragmentos relevantes das respostas obtidas } \\
\hline P1 & $\begin{array}{l}\text { “Não estou realizando nenhuma formação continuada. A Secretaria de Educação faz } \\
\text { uma formação de HP, só que não funciona para a gente. Na verdade, é mais voltado } \\
\text { para área de Pedagogia e não para a gente. Para a área de Ciências, eles não fazem. } \\
\text { Uma vez eu perguntei: Por que não tem um aprofundamento em sistemas humanos } \\
\text { e sistemas ecológicos? O responsável pela formação respondeu: porque isso você } \\
\text { acha na internet." }\end{array}$ \\
\hline P2 & $\begin{array}{l}\text { "Eu gostaria muito de fazer o Mestrado. Muito mesmo! Eu já fiz formações em dança } \\
\text { para complementar meu trabalho. Participei de grupo de danças folclóricas. E como } \\
\text { eu trabalho com futsal já ministrei uma oficina aqui na escola; eu faço curso em } \\
\text { relação ao trabalho de futsal." }\end{array}$ \\
\hline P3 & $\begin{array}{l}\text { "Não tenho interesse por cursos ligados ao ensino de adolescentes e adultos. } \\
\text { Gostaria de fazer formação ligada à Psicologia." }\end{array}$ \\
\hline
\end{tabular}

Fonte: Elaborado pelos autores com base nos questionários aplicados aos docentes.

Considerando que nenhum dos professores possui Pós-Graduação na área específica do ensino de jovens e adultos, a formação continuada seria uma oportunidade de complementar e auxiliar os professores na atuação docente nesta modalidade de ensino, embasando, norteando e aperfeiçoando suas práticas pedagógicas no que se refere ao conhecer, ao fazer, ao ensinar e ao aprender na educação de jovens e adultos.

Percebemos, contudo, que os entrevistados, além de não realizarem nenhuma formação continuada na área específica do ensino com jovens e adultos atualmente, também citam muitas barreiras para participar de cursos até mesmo em suas próprias disciplinas de atuação, seja por falta de oferta seja mesmo por falta de interesse (Quadro 3).

Além disso, o professor P1 citou a Hora Pedagógica (HP), ${ }^{4}$ que corresponde ao tempo da carga horária do professor destinada para formação continuada, planejamento, leituras, estudos e cursos de aperfeiçoamento relacionados ao processo de ensino. O educador salienta que esse tipo de formação ofertada não supre as verdadeiras necessidades dos docentes, uma vez que são ofertadas formações em áreas alheias àquelas em que atuam os professores.

Tendo em vista a formação continuada no espaço escolar, a HP foi criada em 1998 e passou a garantir aos professores 20 horas semanais destinadas à sua formação continuada, deixando a cargo da coordenação pedagógica de cada escola a tarefa de organizar este processo, que deveria ser utilizado para o professor em conjunto com outros professores e coordenação da escola, visando a planejar as aulas, discutir metodologias, avaliar o trabalho realizado, estudar e trocar experiências.

4 Hora Pedagógica - HP: A Portaria no 0071/2015-GABS, ao tratar dos critérios Gerais de Lotação dos professores, refere-se à Hora Pedagógica (HP) como um período de quatro horas semanais reservadas aos docentes das escolas e que são dedicadas aos estudos, pesquisas, planejamento e avaliação, dispendidas fora de sala de aula, na escola e inclusas na carga horária de trabalho, sendo reservada a carga horária de um turno, uma vez na semana, para as atividades da hora pedagógica (BELÉM, 2015). 
Nesta perspectiva, Gadotti e Romão (2002) defendem que o processo formativo pode contribuir para que a qualidade da prática do professor que atua no ensino de adolescentes e adultos melhore, mas é necessário um processo de formação permanente. Isso se dá porque é no decorrer da prática que surgem as perguntas e as dúvidas do professor, de modo que o conhecimento nasce justamente no enfrentamento das dificuldades. Logo, é necessário garantir momentos/espaços para estas questões serem discutidas e resolvidas no coletivo, entre os professores, na troca de experiências, a partir da observação e registro, da análise da prática, do estudo, da avaliação e do planejamento.

A HP, proposta pela Secretaria Municipal de Educação (Semec), deveria ser realizada no espaço da escola, de forma contínua e sistemática, com o acompanhamento e assessoramento do trabalho desenvolvido em sala de aula, com observação, registro, reflexão, avaliação e planejamento, além da pesquisa e do estudo de teorias para fomentar o processo de reflexão sobre a ação.

Outra defensora da formação continuada em espaço escolar é Candau (1996), que toma por base a ideia de que o lócus da formação continuada é a própria escola. Além disso, é necessário que, durante o processo de formação, leve-se em conta o saber docente, pois é no cotidiano da escola que o professor socializa o conhecimento e aprende com os alunos, aplica as teorias, reestrutura seu conhecimento e elabora novos, investiga novas estratégias de intervenção e adquire outras experiências, tudo de acordo com a realidade da escola.

Estimular um ambiente formativo no espaço escolar, trabalhar com o corpo docente e coordenação pedagógica, favorecer a reflexão-crítica, intervir na prática pedagógica, oferecer espaços e tempos institucionalizados, requer o redimensionamento do trabalho da coordenação pedagógica e dos próprios professores (CANDAU, 1996).

Por fim, é importante frisar que o professor P2 tem tentado buscar formações na sua área de atuação na Educação Física e que, apesar do desejo, ainda não conseguiu ingressar no Mestrado. Enquanto isso, P3 cita a vontade em realizar cursos na área de Psicologia, ou seja, fora da sua área de atuação e até mesmo alheia à sua formação acadêmica inicial, inferindo-se, assim, que seu interesse está voltado para uma área diferente da que atua atualmente.

\section{DIFICULDADES E DESAFIOS VIVENCIADOS DURANTE A ATUAÇÃO NO ENSINO DE JOVENS E ADULTOS EM RELAÇÃO À ESCOLA}

Aos professores foi feito o seguinte questionamento: "Quais as principais dificuldades/desafios que você apontaria durante sua atuação nas turmas de jovens e adultos em relação à escola (infraestrutura, material didático/recursos pedagógicos etc.)?" 
Quadro 4 - Dificuldades/desafios em relação à escola

\begin{tabular}{|c|l|}
\hline Docente & \multicolumn{1}{|c|}{ Fragmentos relevantes das respostas obtidas } \\
\hline P1 & $\begin{array}{l}\text { "A infraestrutura é o principal empecilho para qualquer coisa aqui na escola. As } \\
\text { salas são quentes, a climatização não é boa e tem sala que nem climatização tem. } \\
\text { A vida vira um inferno. Se tivesse o mínimo para mim... eu não preciso de muita } \\
\text { coisa." }\end{array}$ \\
\hline P2 & $\begin{array}{l}\text { "A infraestrutura é a pior coisa. A gente não tem uma estrutura adequada para } \\
\text { dar aula. As salas quando não têm ar condicionado... a gente enfrenta problemas } \\
\text { com goteiras, na quadra temos vários pombos defecando na quadra e urinando, a } \\
\text { queda do telhado cai para a quadra, quando chove eu não posso dar aula. Aí eu não } \\
\text { tenho material, quando tem ele dura pouco, porque chega uma bola, duas bolas } \\
\text { aqui para eu usar o ano inteiro, daí eu acabo tendo que tirar do meu bolso para } \\
\text { poder fazer alguma coisa de qualidade." }\end{array}$ \\
\hline P3 & $\begin{array}{l}\text { "Infraestrutura da escola, material didático/recursos pedagógicos e falta de } \\
\text { interesse por parte do poder público." }\end{array}$ \\
\hline
\end{tabular}

Fonte: Elaborado pelos autores com base nos questionários aplicados aos docentes.

Ao considerarmos que a infraestrutura da escola tem papel importante para o processo de ensino e aprendizagem, é fundamental o devido investimento nessa área, uma vez que investir na infraestrutura escolar possibilita diversas oportunidades para que se possa desenvolver um ensino significativo aos alunos.

Apesar disso, a insatisfação com a infraestrutura da escola é recorrente na fala dos professores (Quadro 4), principalmente em relação às salas de aula desconfortáveis e sem climatização, incluindo a descrição detalhada da quadra de esportes da escola e de sua completa falta de estrutura. Além disso, o professor P2 cita que acaba tendo de adquirir materiais para serem usados durante suas aulas, utilizando seus próprios recursos em virtude da falta de materiais disponibilizados pela escola.

Desta forma, observamos a falta de investimento na infraestrutura da escola, incluindo material didático e recursos pedagógicos, não se oferecendo subsídios que levem ao desenvolvimento de experiências pedagógicas positivas, vivências sociais significativas e oportunidades de lazer aos alunos. Isso constitui um desafio para que os docentes consigam realizar um trabalho de qualidade, posto que não possuem condições mínimas para o desenvolvimento de novas metodologias diferenciadas e criativas aos seus alunos.

Segundo Contreras (2002), as instituições escolares são tomadas como esferas públicas democráticas, local em que os alunos, principalmente os das classes sociais populares, aprendem e lutam coletivamente por melhores condições de vida e pela capacitação para uma atuação social. Nesse espaço, os docentes seriam intelectuais críticos com um papel ativo na sociedade.

Nesta concepção, é particularmente importante quando se relaciona aos objetivos da educação voltada para jovens e adultos, contexto em que se pode tratar das questões sociais com mais liberdade e aprofundamento, diferente do ensino de crianças e adolescentes. Como modalidade de Educação, o processo educativo de jovens e adultos é alvo de políticas públicas pontuais e isoladas por parte das esferas governamentais federais, estaduais ou municipais. 
Nesse sentido, enfatizamos a necessidade urgente de investimentos do poder público e de ações da gestão escolar a fim de suprir as necessidades materiais da escola e de oferecer condições mínimas de trabalho aos professores e um ambiente favorável a aprendizagens significativas aos alunos de todas as modalidades de ensino, em especial a voltada a atender jovens e adultos em virtude de suas necessidades específicas e particularidades.

São necessárias, portanto, políticas públicas que visem a promover educação de qualidade a estes alunos, contribuindo para evitar a evasão escolar, ainda tão frequente no contexto da educação no Brasil, em especial nesta modalidade.

\section{DESAFIOS ENFRENTADOS DURANTE A ATUAÇÃO EM RELAÇÃO AO ENSINO DE JOVENS E ADULTOS}

Podemos ver no Quadro 5 aquelas que são as principais dificuldades/desafios que os professores apontaram durante sua atuação nas turmas de educação de jovens e adultos em relação aos alunos (falta de interesse, evasão, dificuldades de aprendizagem, etc.), assim como em relação ao que a escola tem realizado para minimizar os problemas apontados e se este docente conta com o apoio da Secretaria ou da gestão da escola para o combate dos problemas em relação a estes alunos.

Quadro 5 - Dificuldades/desafios em relação aos alunos

\begin{tabular}{|c|c|}
\hline Docente & Fragmentos relevantes das respostas obtidas \\
\hline $\mathbf{P 1}$ & $\begin{array}{l}\text { "A evasão escolar é o principal desafio; falta de interesse de alguns alunos. Eles } \\
\text { têm muita dificuldade de aprendizagem, porque o sistema educacional no Brasil é } \\
\text { um sistema que o docente tem que aprovar, porque a ideia é de que o aluno vai } \\
\text { amadurecendo conforme sua frequência a séries mais adiantadas, no caso, aqui, nas } \\
\text { etapas. Só que isso não é verdade. Se o aluno não aprendeu, ele não vai aprender } \\
\text { lá para frente porque vai ficar mais rápido e mais dinâmico. Quando dizem que o } \\
\text { aluno vai aprender e vai amadurecer... isso é mentira! Isso é uma falácia! Quando } \\
\text { a gente pede apoio para alguma coisa, temos, mas isso é uma questão que é mais } \\
\text { de sala de aula. É pedagógico. Teria que mudar o sistema. O que a coordenação e a } \\
\text { Secretaria de Educação fazem é organizar culminâncias para divulgar o aprendizado } \\
\text { do aluno, mas não quer dizer que ele aprendeu ou vá aprender só porque ele fez } \\
\text { uma culminância. Não tem muito sentido, é mais para se divulgar algo." }\end{array}$ \\
\hline $\mathbf{P 2}$ & $\begin{array}{l}\text { "Falta de interesse, evasão, dificuldades de aprendizagem. Tudo isso enfrentamos aqui. } \\
\text { É um efeito dominó. Você não tem uma infraestrutura adequada; ela vai gerando uma } \\
\text { sensação de descaso e abandono nos alunos. Nós também nos sentimos desestimulados } \\
\text { para ministrar aulas. Temos agora um fenômeno de grupos de adolescentes chegando, } \\
\text { porque eles estão estourando a idade no ensino regular e eles acabam sendo mandados } \\
\text { para a educação de jovens e adultos; então a gente tem um confronto de idade, uma } \\
\text { faixa etária de trabalhadores e de jovens que não se enquadraram no ensino regular. } \\
\text { Acho que também o problema das drogas. Querendo ou não, ele influencia muito, são } \\
\text { jovens que já vem marginalizados do ensino regular, que vem sendo bem na leitura, na } \\
\text { escrita. Uns amadurecem, mas outros... Teve uma mudança de gestão [...] e a gente } \\
\text { está ainda se adaptando à mudança de gestão. Mas a gente tinha uma gestão bem } \\
\text { participativa e essa adaptação está sendo muito difícil agora aqui." }\end{array}$ \\
\hline P3 & “Evasão, dificuldade de aprendizagem. Sim, conto com o apoio da gestão." \\
\hline
\end{tabular}

Fonte: Elaborado pelos autores com base nos questionários aplicados aos docentes. 
A evasão escolar no processo de ensino de jovens e adultos foi citada por todos os professores entrevistados (Quadro 5) como um dos principais desafios nessa modalidade de ensino, inclusive quando citam a falta de interesse e dificuldades de aprendizagem, uma vez que estes fatores também colaboram para os altos índices de abandono dos alunos, influenciando para o fechamento de muitas turmas em virtude da quantidade significativa de discentes que evadem.

Este problema também é destacado nos estudos de Oliveira (1999), para quem as instituições escolares não são adequadas para este grupo de alunos de jovens e adultos do ensino noturno, pois os currículos, os programas, os métodos de ensino, foram originalmente concebidos para crianças e adolescentes, estudantes do ensino regular. Assim, o trabalho escolar pode colocar os jovens e adultos em situações inadequadas para o desenvolvimento real de aprendizagem.

Os altos índices de evasão e repetência são explicados pela inadequação das condições de estudos e dos modelos pedagógicos às necessidades educativas dos alunos, o que indica a falta de sintonia entre a escola e os alunos.

A inovação pedagógica parece ser uma realidade distante nas turmas de educação de jovens e adultos, pois a situação mais comum é de docentes tentando adaptar a metodologia a este público ou, então, que reproduzem a mesma dinâmica de ensino e aprendizagem do sistema regular.

Diante desta constatação, o processo de formação de professores é crucial na busca da melhoria da escola, porém não suficiente para alterar a realidade educacional. É necessário investir na estrutura das escolas, na sua organização e no seu sistema de financiamento para que as mudanças necessárias possam ser concretizadas. Nesta perspectiva, segundo Giroux (1986 apud CONTRERAS, 2002), os professores devem assumir o compromisso com uma sociedade mais justa e democrática, educando os alunos como cidadãos ativos, críticos e compromissados com a construção de uma vida pública digna.

Outro ponto a salientar, conforme observado na resposta do professor P2, corresponde ao novo perfil de alunos das turmas de educação de jovens e adultos. Além dos adultos e idosos que, em sua maioria, são trabalhadores ou que buscam escolarização tardia, atualmente chegam ao ensino noturno muitos jovens que não se adequaram ao ensino regular e se deparam com um confronto de gerações, experiências, vivências e interesses. Isso constitui um outro grande desafio para os professores em relação à seleção de conteúdos e escolha de metodologias que atendam satisfatoriamente a este novo público composto por jovens e adultos.

Além disso, conforme crítica destacada na resposta do professor P1, o atual sistema educacional brasileiro tem focado em "aprovações em massa", nas quais, mesmo que os alunos apresentem lacunas notórias na aprendizagem, acabam sendo promovidos nas respectivas séries, anos, ciclos ou etapas, consolidando as dificuldades de aprendizagem somadas ao longo do seu percurso escolar, fato que também contribui para a evasão escolar e falta de interesse dos alunos, uma vez que esses obstáculos acabam desestimulando os educandos. 
Um estudo sobre tendências curriculares do ensino no processo educativo de jovens e adultos, citado por Ribeiro (2006), identifica três concepções que tentam construir a identidade da modalidade educativa a jovens e adultos. A primeira consiste: i) no reconhecimento dos jovens e adultos como membros de classes populares, excluídos do sistema regular de educação; ii) no reconhecimento do ensino no processo educativo voltado para o atendimento a jovens e adultos como prática política e na iii) capacidade de esta transformar as estruturas sociais produtoras da desigualdade e marginalização social.

Esta concepção tomou corpo, sobretudo, nas décadas de 70 e 80 do século 20. Os conteúdos remetiam diretamente às condições de vida e de trabalho dos alunos. A influência das ideias do educador Paulo Freire foi decisiva para a construção dessa identidade educativa aos que atuam com jovens e adultos.

A segunda relaciona-se às necessidades de aprendizagem de alunos adultos e trabalhadores, entretanto o ensino não pode ser submetido somente às exigências impostas pelo mundo do trabalho ou qualquer outro contexto específico, para não implicar a renúncia ao distanciamento crítico que o contexto educativo propicia aos alunos.

A dedicação à elaboração do próprio conhecimento é uma das especificidades do processo educativo que outras instituições dificilmente poderiam proporcionar.

A terceira linha considera a especificidade do modo de aprender de jovens e adultos que já detêm um considerável conjunto de conhecimentos práticos. Assim, o desafio seria identificar a natureza desses conhecimentos e os estilos cognitivos próprios dos adultos e investigar de que forma estes são mobilizados nas aprendizagens escolares (RIBEIRO, 2006).

Assim, é fundamental a pesquisa para se compreender como os conhecimentos relacionam-se aos contextos sociais dos jovens e adultos, bem como para desenvolver sua capacidade crítica, criativa e de autonomia (RIBEIRO, 1999).

De acordo com Oliveira (1999), o adulto inserido no mundo do trabalho traz consigo toda uma gama de histórias complexas de experiências e conhecimentos acumulados, de reflexões sobre o mundo, sobre si mesmo e as outras pessoas. Na inserção em situações de aprendizagem, essas peculiaridades revelam diferentes habilidades, dificuldades e provavelmente maior capacidade de reflexão sobre o conhecimento e sobre seus próprios processos de aprendizagem.

Diante deste quadro, é necessária uma reconfiguração do papel da escola para atendimento aos alunos da educação de jovens e adultos, uma vez que, ao desconsiderar o perfil dos alunos, a escola não oferece ensino adequado a esses sujeitos em suas diversidades, gerando os frequentes fracassos observados, desestimulando professores e alunos diante desse fenômeno de abandono, posto que a escola tem tido grande influência nessa questão, na medida em que tem negligenciado seu papel quanto às ações efetivas para reduzir os índices de evasão escolar no processo educativo de jovens e adultos.

\section{PROJETOS DE AÇÃO NAS TURMAS QUE ATENDEM JOVENS E ADULTOS}

Aos professores foi questionado se elaboraram algum projeto voltado para atender às especificidades das turmas que atendem jovens e adultos, se o docente encontra-se realizando ou participando de algum projeto no momento ou se tem von- 
tade de instituir alguma ação nesse sentido, e os principais desafios que dificultam a proposta e aplicação de projetos de ação para as turmas de jovens e adultos, conforme o Quadro 6.

Quadro 6 - Projetos propostos e/ou executados no processo educativo de adolescentes e adultos

\begin{tabular}{|c|c|}
\hline Docente & Fragmentos relevantes das respostas obtidas \\
\hline P1 & $\begin{array}{l}\text { "Não tenho e nem participo de nenhum projeto. Eu já tive interesse em criar um } \\
\text { projeto, mas a falta de tempo me tira as forças para tudo. Eu acho que para fazer } \\
\text { um projeto é necessário ter tempo. Não tivemos nenhuma aula extraclasse." }\end{array}$ \\
\hline $\mathbf{P 2}$ & $\begin{array}{l}\text { "O projeto de futsal que eu ministro aqui. O projeto [...] também do violão são } \\
\text { formas de chamar esses garotos para tentar diminuir um pouco esses índices de } \\
\text { violência, comecem a ter mais respeito, impomos também algumas regras para } \\
\text { eles aqui, pela situação da realidade deles aqui no bairro do Guamá. [...] Essa } \\
\text { escola [...], é a que mais funciona aqui, justamente porque a gente tem uma gestão } \\
\text { e equipe de professores interessados e sem uma gestão participativa fica difícil o } \\
\text { funcionamento. O projeto foca mais em tirar esses garotos da rua. Eu não tenho } \\
\text { como estar acompanhando fora de sala. Existe uma cobrança em cima de mim, } \\
\text { o fulano está com nota baixa, barra do projeto. Mas o que que a escola faz por } \\
\text { esses garotos? Porque eu não tenho como ensinar português, história. E eu não } \\
\text { vou barrar o garoto de estar vindo aqui para uma aula do projeto e deixar ele na } \\
\text { rua. Porque vai ser pior. Eu vou na casa deles, eu acompanho a vida deles [...] E eu } \\
\text { não posso relegar isso aqui. Eu percebo a mudança de comportamento. E isso é o } \\
\text { maior resultado do projeto: a mudança comportamental dos meninos do projeto } \\
\text { em relação aos professores, em relação à própria escola." }\end{array}$ \\
\hline P3 & $\begin{array}{l}\text { "Não realizei nenhum projeto e nem penso em criar nenhum. Participo de um } \\
\text { projeto imposto pela Secretaria, que tem o objetivo de pesquisar sobre as cidades } \\
\text { da Região Metropolitana e eu estou trabalhando a cidade de Santa Izabel, mas } \\
\text { o aprendizado não será significativo porque não serão levados para conhecer a } \\
\text { cidade para concretizar na prática o aprendizado." }\end{array}$ \\
\hline
\end{tabular}

Fonte: Elaborado pelos autores com base nos questionários aplicados aos docentes.

Ao considerarmos que as práticas pedagógicas devem ser adequadas ao perfil dos educandos jovens e adultos no que se refere às suas especificidades e vivências, ressaltamos a necessidade de promover metodologias ativas que visem a estabelecer relações significativas entre o conteúdo teórico do currículo selecionado e os interesses e cotidiano desses educandos.

Para isso, é essencial levar em consideração a experiência de vida e a realidade social dos alunos quando são propostos projetos ao público adolescente e de pessoas adultas. Cada projeto deve ser cuidadosamente planejado, considerando fatores como cansaço físico, conflitos com os familiares e colegas, dificuldades em conciliar rotina de estudo e trabalho, obstáculos à aprendizagem, falta de interesse, readequação de conteúdo, entre outros.

Observamos nas falas dos professores (Quadro 6), contudo, que nenhum deles participa ou desenvolve projetos voltados especificamente para os alunos jovens e adultos. Além disso, os professores P1 e P3 sequer demonstram interesse em desenvolver projetos atualmente, e a professora P3 até mesmo faz críticas em relação aos objetivos e metodologias dos projetos propostos pela Secretaria, os quais não suprem as necessidades educacionais conforme o interesse dos alunos. 
Por fim, é importante frisar a resposta do professor P1, que, apesar de desenvolver e participar de projetos destinados aos alunos da escola onde trabalha, explicita que os objetivos destes projetos acabam não focando diretamente nas dificuldades de aprendizagem dos alunos, mas sim numa possível mudança de comportamento destes, uma vez que muitos são vítimas de uma dura realidade social do bairro em que vivem em relação, por exemplo, à violência, tráfico de drogas e marginalidade. Nesse sentido, o professor tenta afastar esses alunos das ruas na medida do possível, a fim de acompanhá-los não somente em relação ao seu rendimento escolar e comportamental, mas tentando evitar que esses educandos abandonem a escola diante da realidade em que vivem.

Assim é a preocupação do professor com os alunos, sua dedicação e interesse na continuidade do aluno em seu percurso educacional, combatendo tanto quanto for possível a evasão escolar. Ainda assim, esta iniciativa é individual; parte de apenas um docente, sem apoio dos outros colegas ou da coordenação ou direção da escola.

Consideramos, também, que a linha mestra da proposta curricular nacional para a EJA é a formação para o exercício da cidadania, sendo fundamental a atuação do próprio aluno na tarefa de construir significados sobre os conteúdos de aprendizagem, reconhecendo os saberes gerados pelo indivíduo dentro do seu grupo cultural, como ponto de partida para gerar novos conhecimentos.

Neste sentido o professor propõe o compartilhamento de responsabilidade sobre a aprendizagem, na busca de alternativas que auxiliem o aluno a aprender a aprender. Ressalta, ainda, a importância de contemplar as diferentes naturezas do conteúdo escolares (conceituais, procedimentais e atitudinais) de maneira integrada no processo de ensino e aprendizagem, visando o desenvolvimento amplo e equilibrado dos alunos, tendo em vista sua vinculação à função social da escola.

Os alunos da EJA possuem histórias de vida singulares, com experiências sociais e familiares específicas; vivem em um mundo com exigências de trabalho e de sobrevivência. A particularidade da EJA se dá em razão das experiências adquiridas pelos alunos no decorrer de sua vida, e que precisam ser consideradas e contextualizadas no âmbito da sala de aula pelos docentes, com recursos e projetos significativos que relacionem os conhecimentos que já detêm com novos, agregando-os no processo educacional para que ganhem sentido e resultem em aprendizado.

Os alunos da EJA enxergam esse momento como uma ruptura da exclusão. De acordo com Britto (2003), um dos motivos segundo o qual os alunos adultos trabalhadores recorrem à educação tardiamente é a necessidade de ressocialização, convivência com outros na mesma condição, e se integrar em atividades gratificantes e que thes motive uma convivência saudável.

Faz-se necessário um pensar sobre esses sujeitos que possuem características específicas para se fazer uma educação que tenha sentido a fim de tornar o processo de ensino aprendizagem significativo, em que a sua trajetória de vida e as dificuldades de aprendizagem não possam interferir neste desenvolvimento. 
Ao chegar no espaço escolar é evidente que estes jovens e adultos sentem vergonha diante dos professores ao realizarem as atividades propostas e avaliações, o que se torna ainda mais complexo quando os docentes e a escola o tratam como um ser de raciocínio infantil ao ofertar salas, material didático e metodologias desenvolvidas de forma igual à utilizada com os alunos da educação infantil ou com crianças do Ensino Fundamental menores. A estes alunos da EJA, é negado recursos pedagógicos e materiais didáticos para sua faixa etária de jovens e adultos, com atividades significativas, relacionadas à sua realidade social.

Gadotti e Romão (2002) ressaltam que o aluno adulto não pode ser tratado como uma criança, precisa ser estimulado, detentor de conhecimentos, fruto de suas experiências de vida. "Muitas vezes tem vergonha de falar de si, de sua moradia, de sua experiência frustrada da infância, principalmente com relação à escola. É preciso que os significados que os alunos da EJA têm em relação à instituição escolar, tudo isso seja verbalizado e analisado." (GADOTTI; ROMÃO, 2002, p. 54).

É necessário que a escola repense seus recursos pedagógicos, seus projetos educativos junto aos alunos da EJA, para que considere suas necessidades e trate-os de forma a corresponder às suas reais expectativas.

\section{CONSIDERAÇÕES FINAIS}

O perfil dos docentes que atuam na EJA possui diferentes tempos de experiência profissional na escola; entre 6 e 11 anos de experiência de atuação na EJA. Os professores trabalham em disciplinas de acordo com sua formação acadêmica: ciências, educação física e pedagogia. São professores com tempo intermediário na carreira docente, sendo dois do sexo masculino e uma do sexo feminino. A faixa etária de dois docentes é de 31 aos 35 anos e um deles apresenta a faixa etária de 45 a 50 anos de idade. Além disso, dois deles trabalham em outros turnos além do noturno, com carga horária semanal, em média, de 20 horas.

Os professores que atuam na EJA revelam pouca perspectiva de formação na Pós-Graduação, pois são cursos importantes no sentido de contribuir com estudos teóricos e pesquisas voltadas para a melhor atuação profissional na área educacional. Segundo os próprios docentes entrevistados, porém, existem determinados entraves para a participação dos professores em cursos de Pós-Graduação; um deles é que ainda são poucas as Universidades que ofertam cursos de Pós-Graduação voltados para a EJA, e outro motivo é a falta de interesse dos docentes em realizar formação na EJA.

As propostas de formação ofertadas pela Secretaria Municipal de Educação de Belém nas Horas Pedagógicas, revelam ainda que não levam em consideração suas necessidades nem seus anseios na sua atuação nas turmas de EJA, uma vez que são realizadas formações com temáticas em áreas alheias àquelas em que atuam os professores, causando desinteresse destes em participar.

A Secretaria de Educação, com seus técnicos e formações continuadas, desconsideram o contexto de atuação pedagógica de professores da Educação de Jovens e Adultos (EJA), os desafios e a realidade do ensino nas escolas, o que fica evidente no depoimento dos professores nesta modalidade de ensino. 
Quanto às dificuldades vivenciadas durante a atuação no ensino de jovens e adultos em relação à escola, os docentes apontaram a falta de infraestrutura da escola, com salas de aula desconfortáveis e sem climatização, a carência de estrutura da quadra de esportes e do desafio de ter de adquirir materiais didáticos para usar durante as aulas com recursos próprios, em decorrência da escassez de materiais didáticos disponibilizados pela escola.

A falta de recursos pedagógicos e de estrutura adequada para o trabalho pedagógico nas escolas acaba comprometendo o próprio ensino e o desenvolvimento de experiências pedagógicas que contribuam para a formação do aluno, oportunidades de práticas esportivas e pedagógicas diferenciadas aos alunos da EJA, causando também evasão escolar dos alunos, outro desafio citado pelos docentes. Isso implica redirecionar o papel das Secretarias de Educação e da gestão escolar, a fim de propiciar o suporte necessário para que os docentes consigam realizar um trabalho de qualidade, com recursos e materiais para atender ao público da EJA e viabilizar o desenvolvimento de novas metodologias diferenciadas aos alunos.

As práticas pedagógicas devem estar voltadas para atender os alunos jovens e adultos no que se refere às suas especificidades e vivências, sendo necessário promover metodologias que estabeleçam relações significativas entre o conteúdo teórico do currículo selecionado e os interesses e cotidiano dos alunos da EJA, levando em consideração a experiência de vida e a realidade social dos alunos. Em razão do contexto das escolas, porém, os professores encontram-se desmotivados em desenvolver projetos voltados para a Educação de Jovens e Adultos; os que existem são formulados e propostos pela Secretaria Municipal de Educação, cujos objetivos e metodologias, de acordo com os docentes entrevistados, não suprem as necessidades educacionais nem o interesse dos alunos.

Apesar de a Legislação vigente assegurar que o ensino a jovens e adultos deve ser oferecido com uma oportunidade de escolarização àqueles que não a tiveram na idade própria do ensino regular, é direito dos educandos desta modalidade de ensino não somente ter garantida a certificação de escolaridade, mas também poder ampliar e compartilhar seus conhecimentos e saberes por meio das vivências no espaço escolar, inclusive desenvolvendo habilidades e competências exigidas no mercado de trabalho.

Desta forma, os conteúdos selecionados e as metodologias utilizadas em sala de aula deveriam ser planejados e postos em prática cuidadosamente nas atividades propostas e desenvolvidas por professores e alunos no dia a dia da escola, com o apoio da gestão escolar.

O poder púbico deveria ser parte fundamental envolvida nesse processo, justamente destinando investimentos e criando políticas públicas para suprir as necessidades específicas desta modalidade de ensino, considerando suas particularidades e singularidades.

Conforme o que se pode analisar nas falas dos professores entrevistados, contudo, dentro dos limites deste estudo constatamos que no atual contexto educacional brasileiro o ensino de jovens e adultos não é devidamente valorizada em relação às diversidades e necessidades de aprendizagem específicas destes educandos. As experiências de vida, o novo perfil das turmas, os interesses diferenciados, as motivações 
específicas e as condições de vida destes alunos, não têm sido considerados e verdadeiramente reconhecidos pelo poder público e, consequentemente, pela gestão escolar, conforme a realidade que observamos em relação à deficiência de oferta de um ensino diversificado e flexível para esses alunos, que seja adequado às singularidades que o público de jovens e adultos necessita.

Aos professores, cabe a grande responsabilidade de acolher esse perfil diferenciado de alunos, adaptando e flexibilizando o ensino para promover metodologias adequadas, criativas e inovadoras para esse público, ficando clara a falta de apoio a este profissional, que já vem de uma formação acadêmica deficiente em relação ao ensino voltado para atender jovens e adultos, seguida de uma formação continuada que não atende às suas necessidades.

É observado, então, um perfil de professor desvalorizado e desmotivado a buscar novas ferramentas capazes de transformar as propostas pedagógicas tradicionais vigentes em escolas que não dispõem de estrutura física nem recursos pedagógicos satisfatoriamente adequados, quantitativa e qualitativamente, para apoiar uma proposta diferenciada de ensino, especialmente no que se refere ao público de jovens e adultos.

O contexto atual do ensino voltado para jovens e adultos evidencia a presença de educandos cada vez mais desestimulados em prosseguir nos estudos, diante de um corpo docente com formação e qualificação deficientes.

As instituições de ensino não oferecem estrutura física adequada ao atendimento desta modalidade e não fomentam novos projetos, o que torna as iniciativas do corpo docente cada vez mais escassas, pois os professores ficam desmotivados a proporem projetos, o que gera efeitos negativos, como a evasão escolar dos alunos, fator que tem contribuído para o fechamento de mais turmas e reduzido ainda mais a oferta desta modalidade de ensino.

O ensino a jovens e adultos permanece sendo desenvolvido de forma improvisada, com planejamento deficiente ou inexistente, em instituições de ensino que não apoiam o corpo docente para oferecer aprendizagem significativa aos educandos, diante de um poder público que não busca criar políticas educacionais que possam transformar este atual quadro.

O contexto do ensino na EJA evidencia um corpo docente com carência de formação e qualificação específicas para desenvolver metodologias e conteúdos voltados para o ensino-aprendizagem de alunos adultos, em instituições de ensino que não oferecem estrutura física adequada, com consideráveis índices de evasão escolar em que o ensino de jovens e adultos ainda é desenvolvido de forma improvisada.

Esta pesquisa, desenvolvida no âmbito da Graduação em curso de Licenciatura em Pedagogia vem contribuir para despertar a importância da pesquisa e da reflexão crítica sobre a realidade das escolas públicas da Rede Municipal de Belém no atendimento à EJA e suas especificidades, e pode contribuir ainda para desenvolver novas pesquisas relacionadas à formação continuada de professores que atuam nesta modalidade, suas necessidades formativas e políticas educacionais que possam ser instituídas. 
Diante desta realidade do ensino voltado para atender jovens e adultos na cidade de Belém/PA, foi enfatizado ser imprescindível trazer à tona as inconsistências entre o que está descrito na legislação e a realidade das escolas que a ofertam, com vistas a fomentar a reflexão e o debate quanto à busca de estratégias que reconheçam esses educandos como sujeitos de direitos, com o objetivo de que o poder público compreenda a importância de investimento nesta modalidade de ensino.

Neste sentido, é urgente que a escola e seus diversos sujeitos repensem e ressignifiquem as suas práticas de gestão e metodologias pedagógicas contemplando as singularidades dos educandos jovens e adultos, os quais ainda têm sido considerados sujeitos "invisíveis" em relação ao seu direito de acesso a uma educação pública significativa e de qualidade em nosso país.

O estudo proposto não teve como objetivo esgotar o assunto sobre o contexto de atuação e as principais dificuldades e desafios enfrentados pelos docentes nas escolas que ofertam turmas de EJA, nem os resultados têm a pretensão de serem tomados como generalizações a todas as pesquisas. O referencial teórico, a metodologia, o contexto escolar, as contribuições e críticas apresentadas em relação à formação docente, aos desafios e dificuldades enfrentados pelos docentes, porém, poderão servir como contribuição para outras pesquisas a serem desenvolvidas e aos demais interessados nesta abordagem, e poderá servir para a consulta dos envolvidos no processo formativo de docentes da EJA, nas escolas.

\section{REFERÊNCIAS}

BELÉM. Resolução CMEB n 020/2011, de 12 de junho de 2011. Estabelece Diretrizes para a oferta da Educação de Jovens e Adultos, em nível de Ensino Fundamental na rede de escolas públicas municipais de Belém/PA. Diário Oficial do Município de Belém, ano 52, n. 11.878, p. 4, 2011.

BELÉM. Portaria no 0071/2015 - GABS, de 20 mar. 2015. Dispõe sobre os critérios a serem adotados para a lotação de pessoal da Secretaria Municipal de Educação de Belém e dá outras providências. Diário Oficial do Município de Belém, ano 56, n. 12.771, p. 6-9, 2015.

BRASIL. Constituição da República Federativa do Brasil de 1988. Brasília: Presidência da República, 1988. Disponível em: tinyurl.com/czskwlw. Acesso em: 29 nov. 2019.

BRASIL. Lei no 9.394, de 20 de dezembro de 1996. Estabelece as diretrizes e bases da educação nacional. Brasília: Presidência da República, 1996. Disponível em: tinyurl.com/3rq54tt. Acesso em: 29 nov. 2019.

BRASIL. Parecer CEB no 11/2000. Dispõe sobre as Diretrizes Curriculares para Educação de Jovens e Adultos. Brasília: MEC, 2000. Disponível em: tinyurl.com/tyfd3be. Acesso em: 29 nov. 2019.

BRASIL. Secretaria de Educação Fundamental. Referenciais Curriculares para a educação de jovens e adultos: segundo segmento do Ensino Fundamental, 2002.

BRITTO, Luiz Percival Leme. Contra o consenso: cultura escrita, educação e participação. Campinas, SP: Mercado de Letras, 2003.

CANDAU, V. M. F. Formação continuada de professores: tendências atuais. In: REALI, A. M. M. R.; MIZUKAMI, M.G. N. (org.). Formação de professores: tendências atuais. São Carlos: Edufscar, 1996. p. 139-165. CONTRERAS, J. A autonomia dos professores. São Paulo: Cortez, 2002.

EHRHARDT. N. Aprendendo com a Educação de Jovens e Adultos. In: SCHEIBEL, M. F.; LEHENBAUER, S. (org.). Saberes e singularidades na Educação de Jovens e Adultos. Porto Alegre: Mediação, 2010. p. 151163.

FREIRE, P. A educação na cidade. São Paulo: Cortez, 1991.

FREIRE, P. Pedagogia do oprimido. Rio de Janeiro: Paz e Terra, 2005.

GADOTTI, M.; ROMÃO, J. E. (org.). Educação de Jovens e Adultos: teoria, prática e proposta. 5. ed. São Paulo: Cortez; Instituto Paulo Freire, 2002. 


\section{Rountexto \\ \&Educaçẵo}

MAIA, C. M. Educação de Jovens e Adultos: possibilidades? In: SCHEIBEL, M. F.; LEHENBAUER, S. (org.). Saberes e singularidades na Educação de Jovens e Adultos. Porto Alegre: Mediação, 2010. p. 141-151.

OLIVEIRA, M. K. Jovens e adultos como sujeitos de conhecimento e aprendizagem. Revista Brasileira de Educação, n. 12, p. 59-73, 1999.

RIBEIRO, V. M. A formação de educadores e a constituição da Educação de Jovens e Adultos como campo pedagógico. Educação \& Sociedade, v. 20, n. 68, 184-201, 1999.

RIBEIRO, V. M. Analfabetismo e alfabetismo funcional no Brasil. São Paulo: Instituto Paulo Montenegro, 2006.

ROSA, Sonia Maria Oliveira de. Formação continuada dos professores da EJA: ressignificando a prática. In: SCHEIBEL, Maria Fani; LEHENBAUER, Silvana (orgs.). Saberes e Singularidades na Educação de Jovens e Adultos. 2. ed. Porto Alegre: Mediação, 2010. p. 163-168.

SANTOS, L. L. C. P. Dimensões pedagógicas e políticas da formação contínua. In: VEIGA, I. P. A. (org.). Caminhos da profissionalização do magistério. 3. ed. Campinas: Papirus, 1998. p. 123-136.

SEMEC. Caderno de Formação. Educação de Jovens e Adultos. Belém: Semec, 2002.

SCHEIBEL, M. F.; LEHENBAUER, S. (org.). Saberes e singularidades na Educação de Jovens e Adultos. Porto Alegre: Mediação, 2010. 